\title{
COVID 19 and the Veterinary Community
}

\section{Varghese Samuel Mathai*}

Department of Senior Veterinary Surgeon, Animal Specialist clinic, Dubai, United Arab Emirates

*Corresponding Author: Varghese Samuel Mathai, Department of Senior Veterinary Surgeon, Animal Specialist clinic, Dubai, United Arab Emirates.
Received: June 28, 2020

Published: August 01, 2020

(C) All rights are reserved by Varghese Samuel

Mathai.
We would have never thought of Living through pandemic let alone having one in this lifetime. COVID-19 has presented us with a lot of unprecedented circumstances, loss of loved ones and a chance to retrospect on the inadequacies of veterinary-human medicine interactions.

The challenge we face as veterinarians having responsibility towards the general public has increased. As a veterinarian this pandemic has brought us to adopt more stringent biosecurity protocols when dealing with companion and farm animals with diseases. Also, strict laws and precise enactment of these laws regarding wildlife trade is the need of the hour all over the world. Improving public knowledge on health concerns and zoonosis when it comes to consumption and domesticating wildlife needs to be given more emphasis in the future.

Veterinary practices across the world has started to change the way they practice and one aspect that has gained much traction during the pandemic is Telemedicine. Behavioural therapy in companion animal medicine is also much more important now as most of the pet parents are staying at home for work. PPE kits have become more expensive and not readily available and as a result the need for careful use and re-sterilisation. Veterinary microbiologists need to rise up to the occasion and deliver on the much needed inputs which is the need of the hour.

Scientists around the globe are racing to develop tests, treatments, and vaccines to combat the COVID-19 disease and many of these developments have a veterinary basis. This is a proud fact but also bringing into the light the need of open publications and more emphasis on the dissemination of various research studies into the public domain than ever before. Even though one health is an emerging field, the push for more human medicine and veterinary medicine interactions in key areas like zoonotic diseases needs to be given more emphasis. Governments and private funding in this area of interest will certainly prove to be of great help in the future containment strategies.

\section{Assets from publication with us}

- Prompt Acknowledgement after receiving the article

- Thorough Double blinded peer review

- Rapid Publication

- Issue of Publication Certificate

- High visibility of your Published work

Website: www.actascientific.com/

Submit Article: www.actascientific.com/submission.php Email us: editor@actascientific.com

Contact us: +919182824667 